\title{
Non-celiac gluten sensitivity - why worry?
}

\author{
Knut E A Lundin ${ }^{1,2,3}$
}

\begin{abstract}
Wheat, once thought to be a critical ingredient in a healthy diet, has become a major threat, according to public opinion. The term non-celiac gluten sensitivity has been widely adopted to describe a clinical entity characterized by symptoms induced by gluten without the diagnostic criteria found in other gluten-related disorders. However, it has not been shown that gluten per se is involved, and it can be debated if the condition is a disease. Nevertheless, a large number of individuals go gluten-free, avoiding wheat, rye and barley, even without a defined medical cause. In a study in BMC Medicine, Volta and colleagues from Italy report on a large, multicenter attempt to enumerate the prevalence of non-celiac gluten sensitivity in secondary gastroenterology care. They found that approximately $3 \%$ of their more than 12,000 patients fulfilled their criteria for non-celiac gluten sensitivity. However, we are still challenged with finding stricter clinical criteria for the condition, developing a usable clinical approach for gluten challenge in these individuals, and understanding the pathogenesis of the condition.

Please see related article http://www.biomedcentral.com/1741-7015/12/85.

Keywords: Celiac disease, Diagnosis, FODMAP, Gluten, Gluten-free diet, Irritable bowel syndrome, Multicenter study, Non-celiac gluten sensitivity
\end{abstract}

\section{Background}

In the Western world, consumption of wheat has increased over the last half-century [1], as have the standard of living and life expectancy. Wheat is now more desirable than rice in large populations in China and India [2]. However, we now see a trend in Europe, Australia, New Zealand and the US to avoid dietary wheat. The numbers are uncertain, but prevalence up to $6 \%$ has been suggested. This trend is so pronounced that the consumption of wheat has declined [1], and it raises important questions. Are disease mechanisms involved? Is there any health benefit or risk from avoiding gluten? Is the trend solely due to public pressure? Could all those consumers be mistaken? Why adopt a strict, restrictive diet without a well-defined medical reason?

'Gluten' as a term is complicated. A gluten-free diet (GFD) is one without wheat, rye and barley. Gluten also refers to the glue-ish mass remaining after washing wheat flour with water. In addition, gluten describes the storage proteins found in cereals, those proteins that have well-

\footnotetext{
Correspondence: k.e.a.lundin@medisin.uio.no

'Department of Gastroenterology, Oslo University Hospital Rikshospitalet, N-0498 Oslo, Norway

${ }^{2}$ Centre for Immune Regulation, University of Oslo, N-0316 Oslo, Norway

Full list of author information is available at the end of the article
}

known baking properties. The term 'gluten-related disorders' is also complicated [3,4]. At least three clinical entities are recognized: celiac disease $(\mathrm{CD})$, wheat allergy, and non-celiac gluten sensitivity (NCGS). CD is a gluteninduced inflammatory disorder of the small intestinal mucosa, with typical serology comprising immunoglobulin (Ig) A antibodies to the enzyme tissue transglutaminase or deamidated gliadin peptides. Wheat allergy is an acute anaphylactic condition, with the presence of IgE to gluten. Lastly, NCGS is characterized by clinical signs induced by gluten, but without the same diagnostic criteria. Thus, NCGS is so far defined only by clinical terms - with all the problems we often see when clinicians lack strict criteria. The link to and comparison with irritable bowel syndrome is obvious. Irritable bowel is also diagnosed clinically, and can be treated by food restriction [5], but whether these entities really overlap remains to be seen.

\section{Non-celiac gluten sensitivity versus celiac disease}

In a study published in BMC Medicine, Volta and colleagues report a multicenter, prospective study on prevalence of NCGS [6]. Thirty-seven specialist centers participated, all with expertise in gluten-related disorders. In Italy, such centers are accredited by the government and are responsible for reimbursement for GFD.

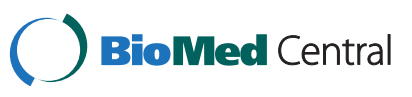

(C) 2014 Lundin; licensee BioMed Central Ltd. This is an Open Access article distributed under the terms of the Creative Commons Attribution License (http://creativecommons.org/licenses/by/4.0), which permits unrestricted use, distribution, and reproduction in any medium, provided the original work is properly cited. 
The study evaluated 12,255 patients. The authors found 486 patients $(3.19 \%)$ with NCGS, with a mean age 38 years, and a female to male ratio of 5.4:1. At the same time, they identified CD in 340 patients (2.77\%). In the NCGS population, half of them had signs compatible with irritable bowel syndrome and received that diagnosis as well. Other frequent findings were allergies, autoimmune diseases and a close relative with CD. Laboratory tests showed low levels of ferritin, folic acid and vitamin D, but only in a minority. They found increased levels of IgG to gluten, but only in $25 \%$ of their patients. Disease controls were not reported. The authors should be congratulated for their efforts.

Although well conducted, there are some comments to be made. Firstly, the cut-off for diagnosis of NCGS in the study was not clear. The authors used a 60 -item doctoranswered questionnaire with 'yes/no' items. There was no requirement for a given number of positive answers for a diagnosis. It appears that the diagnosis of NCGS was done 'clinically'. Secondly, it is unclear if the participating clinicians in fact approved the patient's use of their GFD. Thirdly, the study did not include a systematic placebocontrolled food challenge. This is often considered the gold standard for food intolerance, but is clinically problematic [7].

The study of Volta et al. showed NCGS in approximately $3 \%$ of referred patients. How this relates to the general population is unclear. Other reports have shown wide variations in prevalence. A study from a referral US center found NCGS in 6\% of patients [4]. A US-based population survey study found a low prevalence of NCGS [8], but the survey was not designed to detect NCGS. A UK-based population study showed that 13\% considered themselves as gluten-sensitive, and 3.7\% consumed a GFD (most of them without a CD diagnosis) [9]. In New Zealand, 5\% of children are on a GFD [10]. Thus, it is reasonable to accept that a noteworthy proportion of the Western population is on a GFD.

Are there reasons to worry about people having a GFD? We have no estimates on any health benefits of a GFD in the NCGS population, in contrast to the known benefits in the $\mathrm{CD}$ population. We do not yet have any proof that a GFD has a negative health effect on the NCGS population, whereas there is some evidence that it may in $\mathrm{CD}$, because treated patients show signs of nutritional deficiency [11]. Thus, the short answer is that in the case of NCGS a GFD is neither medically needed nor detrimental. However, NCGS has many similar aspects to irritable bowel syndrome, a condition that has a severe impact on a patient's quality of life and represents a very significant financial burden on all Western health care system. It is therefore necessary to developing a usable clinical approach for gluten challenge in individuals with NCGS.
Well, then, how to investigate? It depends on whether the patient is still on a gluten-containing diet or a GFD. The objective signs of $\mathrm{CD}$, with serology and mucosal inflammation, normalize when a patient with $\mathrm{CD}$ commences a GFD. Thus, serological testing with anti-tissue transglutaminase IgA should be done before any clinician advocates a GFD. If the patient is already gluten-free, another approach should be taken. In fact, CD is not frequent in the NCGS population, and a clinical response to gluten withdrawal is not proof that the patient has $C D$ [12-14]. Genetic analysis for human leukocyte antigens DQ2 and DQ8 is useful, because it is highly unlikely that $\mathrm{CD}$ is the causal disease in the absence of these genetic variants $[15,16]$. Further investigation of possible $C D$ involves gluten challenge of two to six weeks' length or more where the aim is to provide objective signs of $C D$ $[17,18]$.

Gluten challenge or withdrawal to prove or disprove NCGS is complicated. A blinded challenge approach would be ideal, but the standard test with flour in capsules is problematic and rarely used [7]. A good placebo food preparation is essential, and has been developed in Australia $[19,20]$. Further understanding of NCGS will require that other groups also introduce blinded, placebocontrolled challenge protocols. It has been questioned if NCGS actually exist, or if it is caused by sensitivity to fermentable carbohydrates that are abundant in glutencontaining cereals [20]. To further complicate the matter, non-gluten proteins have been proposed to be important [21], but for the wheat-sensitive patient, this does not really matter. Moreover, the use of a wide array of symptom evaluations and lack of a standardized symptom scoring form represent major obstacles to further progress.

\section{Conclusions}

The use of a GFD without a well-defined medical reason has reached considerable proportions in many Western societies. The clinical entity NCGS resembles, and may well be a part of, irritable bowel syndrome. The diagnosis of both conditions is based on clinical work-up; objective biomarkers are not available and may be difficult to develop. NCGS may be caused by improper immune responses, intolerance to poorly digestible and fermentable substances in the wheat, or a combination of these. NCGS is a burden for the affected individuals and for the healthcare system trying to provide proper help for them. Future research should address whether gluten really is involved, and if a manageable, clinically acceptable, placebo-controlled investigation procedure can be developed. We should aim provide relief for those who really benefit from dietary restriction, without overtreating those who would benefit from more temporary interventions. 


\section{Abbreviations}

CD: celiac disease; GFD: gluten-free diet; Ig: immunoglobulin; NCGS: non-celiac gluten sensitivity.

\section{Competing interest}

The author declares that he has no competing interests.

\section{Acknowledgements}

The Health Authorities of South-Eastern Norway and the Extra Fund is acknowledged for supporting our research.

\section{Author details}

'Department of Gastroenterology, Oslo University Hospital Rikshospitalet, N-0498 Oslo, Norway. ${ }^{2}$ Centre for Immune Regulation, University of Oslo, N-0316 Oslo, Norway. ${ }^{3}$ Faculty of Medicine, University of Oslo, N-0316 Oslo, Norway.

Received: 23 April 2014 Accepted: 23 April 2014 Published: 23 May 2014

\section{References}

1. Kasarda D: Can an increase in celiac disease be attributed to an increase in gluten content of wheat as a consequence of wheat breeding? J Agric Food Chem 2013, 61:1155-1159.

2. Makharia G, Mulder CJJ, Goh KL, Ahuja V, Bai JC, Catassi C, Green PHR, Gupta SD, Lundin KEA, Ramakrishna BS, Rawat R, Sharma H, Sood A, Watanabe C, Gibson PR: Issues associated with the emergence of coeliac disease in the Asia-Pacific region: a working party report of the World Gastroenterology Organization and the Asian Pacific Association of Gastroenterology. J Gastroenterol Hepatol 2014, 29:666-677.

3. Ludvigsson JF, Leffler DA, Bai JC, Biagi F, Fasano A, Green PH, Hadjivassiliou M, Kaukinen K, Kelly CP, Leonard JN, Lundin KE, Murray JA, Sanders DS, Walker MM, Zingone F, Ciacci C: The Oslo definitions for coeliac disease and related terms. Gut 2013, 62:43-52.

4. Sapone A, Bai JC, Ciacci C, Dolinsek J, Green PHR, Hadjivassiliou M, Kaukinen K, Rostami K, Sanders DS, Schumann M, Ullrich R, Villalta D, Volta U, Catassi C, Fasano S: Spectrum of gluten-related disorders: consensus on new nomenclature and classification. BMC Med 2012, 10:13-25.

5. Halmos EP, Power VA, Shepherd SJ, Gibson PR, Muir JG: A diet low in FODMAPs reduces symptoms of irritable bowel syndrome. Gastroenterology 2014, 146:67-75.

6. Volta U, Bardella MT, Calobro A, Troncone R, Corazza GR: An Italian prospective multicentre survey on patients suspected of having non-gluten sensitivity. BMC Med, 12:85.

7. Lundin KE, Alaedini A: Non-celiac gluten sensitivity. Gastrointest Endoscopy Clin N Am 2012, 22:723-734.

8. DiGiacomo DV, Tennyson CA, Green PH, Demmer RT: Prevalence of gluten-free diet adherence among individuals without celiac disease in the USA: results from the Continuous National Health and Nutrition Examination Survey 2009-2010. Scand J Gastroenterol 2013, 48:921-925.

9. Aziz I, Lewis NR, Hadjivassiliou M, Winfield SN, Rugg N, Kelsall A, Newrick L, Sanders DS: A UK study assessing the population prevalence of self-reported gluten sensitivity and referral characteristics to secondary care. Eur J Gastroentero Hepatol 2014, 26:33-39.

10. Tanpowpong P, Ingham TR, Lampshire PK, Kirchberg FF, Epton MJ, Crane J, Camargo CA: Coeliac disease and gluten avoidance in New Zealand children. Arch Dis Child 2012, 97:12-16.

11. Hallert C, Grant C, Grehn S, Grännö C, Hultén S, Midhagen G, Ström M, Svensson $\mathrm{H}$, Valdimarsson T: Evidence of poor vitamin status in coeliac patients on a gluten-free diet for 10 years. Aliment Pharmacol Ther 2002, 16:1333-1339.

12. Kaukinen K, Turjanmaa K, Mäki M, Partanen J, Venäläinen R, Reunala T, Collin $P$ : Intolerance to cereals is not specific for coeliac disease. Scand J Gastroenterol 2000, 35:942-946.

13. Brottveit M, Ráki M, Bergseng E, Fallang LE, Simonsen B, Løvik A, Larsen S, Løberg EM, Jahnsen FL, Sollid LM, Lundin KEA: Assessing possible celiac disease by an HLA-DQ2-gliadin tetramer test. Am J Gastro 2011, 106:1318-1324.

14. Brottveit M, Vandvik PO, Wojniusz S, Løvik A, Lundin KEA, Boye B: Absence of somatization in non-coeliac gluten sensitivity. Scand J Gastroenterol 2012, 47:770-777.
15. Coburn JA, Voort JLV, Lahr BD, Van Dyke CT, Kroning CM, Wu TT, Gandhi MJ, Murray JA: Human leukocyte antigen genetics and clinical features of self-treated patients on a gluten-free diet. J Clin Gastroenterol 2013, 47:828-833.

16. Kabbani TA, Vanga RR, Leffler DA, Villafuerte-Galvez J, Pallav K, Hansen J, Mukherjee R, Dennis M, Kelly CP: Celiac disease or non-celiac gluten sensitivity? An approach to clinical differential diagnosis. Am J Gasteroenterol, in press. http://www.ncbi.nlm.nih.gov/pubmed/24619056.

17. Leffler D, Schuppan D, Pallav K, Najarian R, Goldsmith JD, Hansen J, Kabbani $T$, Dennis M, Kelly CP: Kinetics of the histological, serological and symptomatic response to gluten challenge in adults with coeliac disease. Gut 2013, 62:996-1004.

18. Lähdeaho ML, Mäki M, Laurila K, Huhtala H, Kaukinen K: Small-bowel mucosal changes and antibody responses after low- and moderate-dose gluten challenge in celiac disease. BMC Gastroenterol 2011, 11:129-138.

19. Biesiekierski JR, Newnham ED, Irving PM, Barrett JS, Haines M, Doecke JD, Shepherd SJ, Muir JG, Gibson PR: Gluten causes gastrointestinal symptoms in subjects without celiac disease: a double-blind randomized placebo-controlled trial. Am J Gastroenterol 2011, 106:508-514.

20. Biesiekierski JR, Peters SL, Newnham ED, Rosella O, Muir JG, Gibson PR: No effects of gluten in patients with self-reported non-celiac gluten sensitivity after dietary reduction of fermentable, poorly absorbed, shortchain carbohydrates. Gastroenterology 2013, 145:320-328.

21. Junker Y, Zeissig S, Kim SJ, Barisani D, Wieser H, Leffler DA, Zevallos V, Libermann TA, Dillon S, Freitag TL, Kelly CP, Schuppan D: Wheat amylase trypsin inhibitors drive intestinal inflammation via activation of toll-like receptor 4. J Exp Med 2012, 209:2395-2408.

\subsection{6/1741-7015-12-86}

Cite this article as: Lundin: Non-celiac gluten sensitivity - why worry? BMC Medicine 2014, 12:86

\section{Submit your next manuscript to BioMed Central and take full advantage of:}

- Convenient online submission

- Thorough peer review

- No space constraints or color figure charges

- Immediate publication on acceptance

- Inclusion in PubMed, CAS, Scopus and Google Scholar

- Research which is freely available for redistribution 